\title{
Fashion Design in ROWE Fashion PLMs
}

\author{
Edit Csanák DLA \\ Óbuda University Sándor Rejtő, Faculty of Light Industry and Environmental Engineering, \\ Institute of Product Design, HUNGARY
}

Received: January 02, 2019; Accepted: January 21, 2019; Published: January 22, 2019

*Corresponding author: Edit Csanák DLA, Óbuda University Sándor Rejtő Faculty of Light Industry and Environmental Engineering, Institute of Product Design, 1034 Budapest, Doberdó út 6. HUNGARY, Email: csanak.edit@rkk.uni-obuda.hu

\begin{abstract}
Fashion designers working in the Results Only Work Environment (ROWE) face new challenges. The contemporary practice encourages the use of new working methods in the PLM, placing the essential tools of the profession in a new approach. Since new times are bringing new demands, as a result of the "legitimate" progress, contemporary fashion design practice seems to change the traditional methods resulted in a visible change of the aesthetics and quality on the fashion market. In part, this difference arises from the difference between creative and problem-solving thinking applied during the design process which manifests in different types of fashion designs (sketches, drawings, artworks) capable of displaying the artistic idea and intention.
\end{abstract}

A big amount of literature is theorizing on the process of creative cognition, however slightly dealing with the topic of fashion designing, and the genre of fashion design. Studying the different types of works (applied at a given stage of the design process) confirms that the use of new working methods has a lot to do with the Fast Fashion phenomenon, the changed aesthetics of today's fashion, and they have much attachment to the changed working methods of the millennial creators. Rapid and "instant" application of shapes, cut lines, colors, and patterns is having a strong visual, quality and technological impact on collections, and hence on the economic status of the fashion world, for more than ten years.

This article is rather a new approach by a designer as a scientific statement based on an empirical study and pragmatic findings. However, the author believes that the use of results can help make fashion more eloquent and sustainable.

Keywords: Fashion Design; Creative Process; ROWE; PLM; Sustainable Fashion

\section{Introduction}

Fashion surrounds us! Though the fashion apparel industry has never been as risky as it is today, thousands of start-ups are created every year, and the expansion of the fashion market can be considered lasting. Even though the fashion industry, which employs millions of artists and non-artists worldwide, has never had a lousy reputation as today, newcomers looking for a job have a good chance of finding their dream-job on the fashion market [5]. Voices against enormous environmental, economic and social damage caused by the global fashion industry are getting louder. Sustainable fashion has become a fundamental trend for all professional forums; has developed methods and literature, and has professional associations and renowned professionals who have gained a reputation around the world. Sustainable trends enjoy the support of the iconic representatives of the fashion world. Sustainability has become a motto of the profession: a password, a symbol of economic and social responsibility [27]. At the same time, "sustainable fashion" is many times used just a like a phrase, which can be considered a 'just-another-trend' created by Fashion, under which fake-brand identities are created, and consumers are misrepresented. This article has been written for those who believe that the sustainability of the fashion industry is primarily based on the conscious daily work of designers, and not just the enthusiastic support of the concept and the follow-up of principles. The relationships revealed in the thesis are expected to help improve their work.

\section{Key challenges of the global fashion industry and the challenger}

Nowadays technology and the fashion industry are considered two sides of the same coin; young fashionistas drive fashion and managed by celebrity-bloggers. Season boundaries are remaining blurred, and fashion trend forecasting became a flourishing business. In order to adapt to confusing market behavior, the clothing industry began to apply data analyzes; ranking service, strategic consulting, customer behavior analysis and customer satisfaction measurement became mandatory; more and more brands are turning to algorithms to increase their sales. This decade will also be recorded in the fashion history as the decade when the fashion industry faced new phenomena and new challenges; the millennium paradigm shift and the IT revolution affect fashion as any other area of life.

Around 2010, the fashion world faced serious difficulties, which could not be solved quickly. The saturated market, unsold stocks, uncertain customers, loss of credibility, false brand DNA, style-theft and fast-growing e-commerce were circumstances pretending to be meant a new-normal state of the market. In retrospect, the roots of depression have been more profound than expected, so the fashion world had to start analyzing what signs of phenomena remained ignored and started to develop different strategies. Shortly before, a relatively new phenomenon occurred, which, like a virus, infected the cumbersome, robust apparatus of the RTW industry. The disease was called Fast Fashion. Its mechanism was simple, and the application of the method has acted as a drug for the organizational structure of 
companies, causing irreversible changes in their corporate system and marketing strategy. The epidemic spread very quickly, not sparing any market category [2], even the prestigious Haute Couture. With the dramatic increase in demand for diversity, interactivity, and virtuality, the industry's work methods and requirements have also changed. Prior to that, talent, remarkable craftsmanship and creative skills, as well as marketable technology knowledge (tailoring, patterning, knowledge of the manufacturing process, etc.) were important, from the first decade of the new millennium to rapid decisionmaking, the IT knowledge (software, applications, online tools) along with the confident use of these, new technologies became the key skills. Most job advertisements have begun to look for employees with basic professional knowledge who are skilled in using CAD systems and are capable of teamwork [10]. Employers were almost never interested in the candidate's manual skills. Almost none of the employers was no longer interested in the manual skills of the candidate. However, the analysis of freehand sketches, fashion drawings, and quality of the technical drawing confirms that lack of manual skills is linked to the candidate's creative abilities.

Designers were always sensitive people; this made their creatures special. Towards the end of the second decade of the millennium, new attitudes to creativity, such as rapid planning, confident decision-making, have cut down on the essential process of design work, questioning the importance of one or another stage of the process and their professional relevance. New settings are worthy of further consideration due to their long-term effects.

\section{The Fast Fashion syndrome: Identification of a phenomenon}

The roots of Fast Fashion are in the development of Quick Response (QR), which spread to American apparel manufacturers in the late 1970s and 1980s. QR is an approach that satisfies customers' needs by providing the right amount and quality at the right time at the right price [16]. The term "Fast Fashion" was first used in the late 1990s and early 2000s to describe fashion goods that were created quickly with a low budget [7]. Shane Watson, the reporter of The Sunday Times (London), first announced the changes in the fashion world in 2006, when he wrote: It is not designers who dictate fashion today. Something 'went wrong'... [26]. The business model first introduced by Inditex Group, as stated by the Inditex CEO, José María Castellano Ríos, was very simple: Link customer demand to manufacturing, and link manufacturing to distribution [1]. When the professional associations first time took a commitment it is so easy to copy this method that might change the fashion scene forever, the infection has already taken place.

\section{The 3P and the factor of time}

The motto of the new millennium is 3P. The Slow Fashion movement, which focuses on the environment, human aspects and sustainability, contradicts Fast Fashion trends. Its characteristics (short production time, fast delivery, intense market competition, high demands, and quick turnover) are in line with the era's paradigm. The time-price-value rate is a primary feature of laborintensive products, such as clothing. The illustration of the classic method is shown in Figure 1.

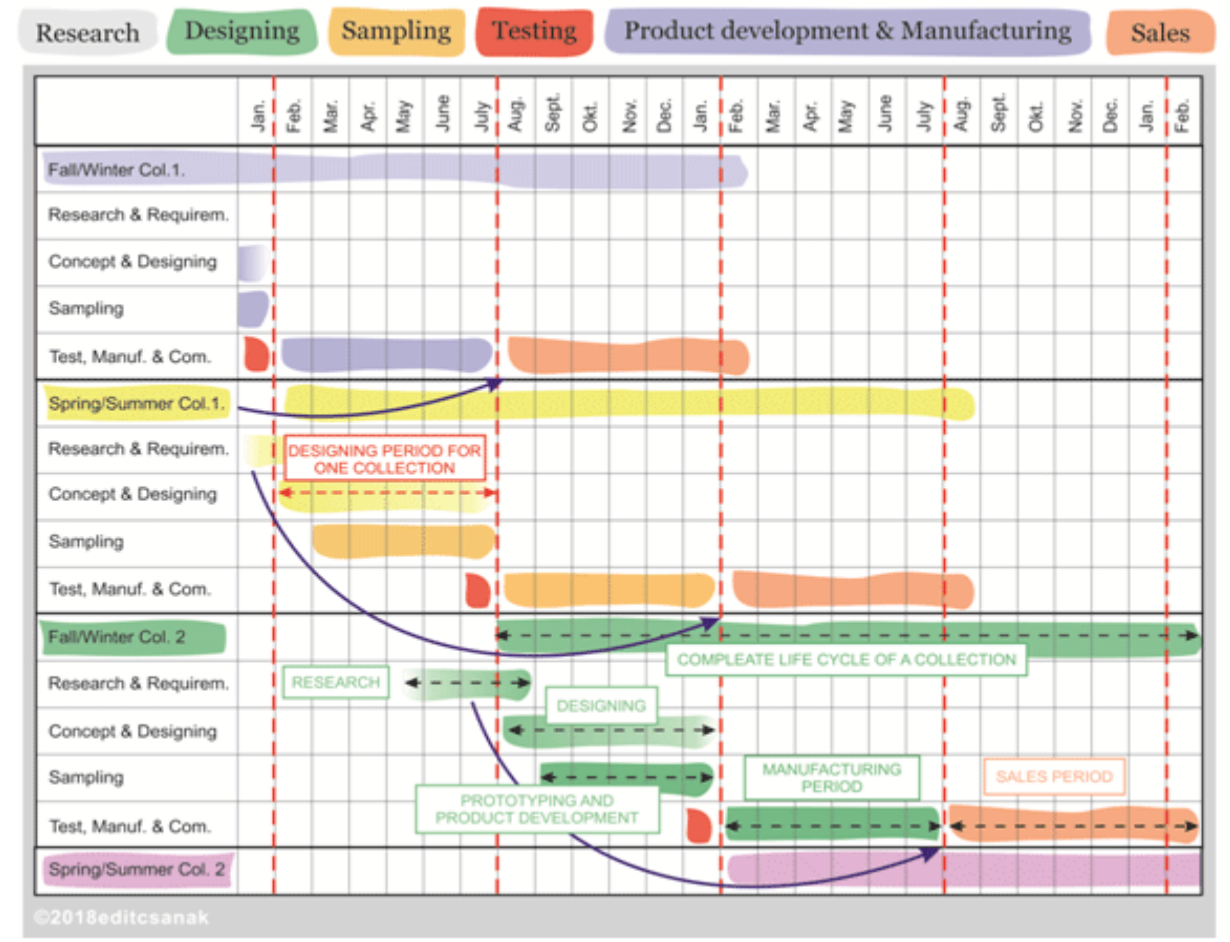

Figure 1: Schedule of 'traditional' collection development according to the general methodology 
According to the classic method, the development of a collection covers an average of six months, and the life cycle of a product family lasts one and a half years. The transition between seasons maintains the same burden on all supply chain participants (Fig 1) [7]. For comparison, the Fast Fashion
Collections are created in a much shorter time. Accordingly, if a fresh capsule collection is created every week, it will result in at least 40 and up to 52 new collections ("micro-seasons") per year, as illustrated in Figure 2.

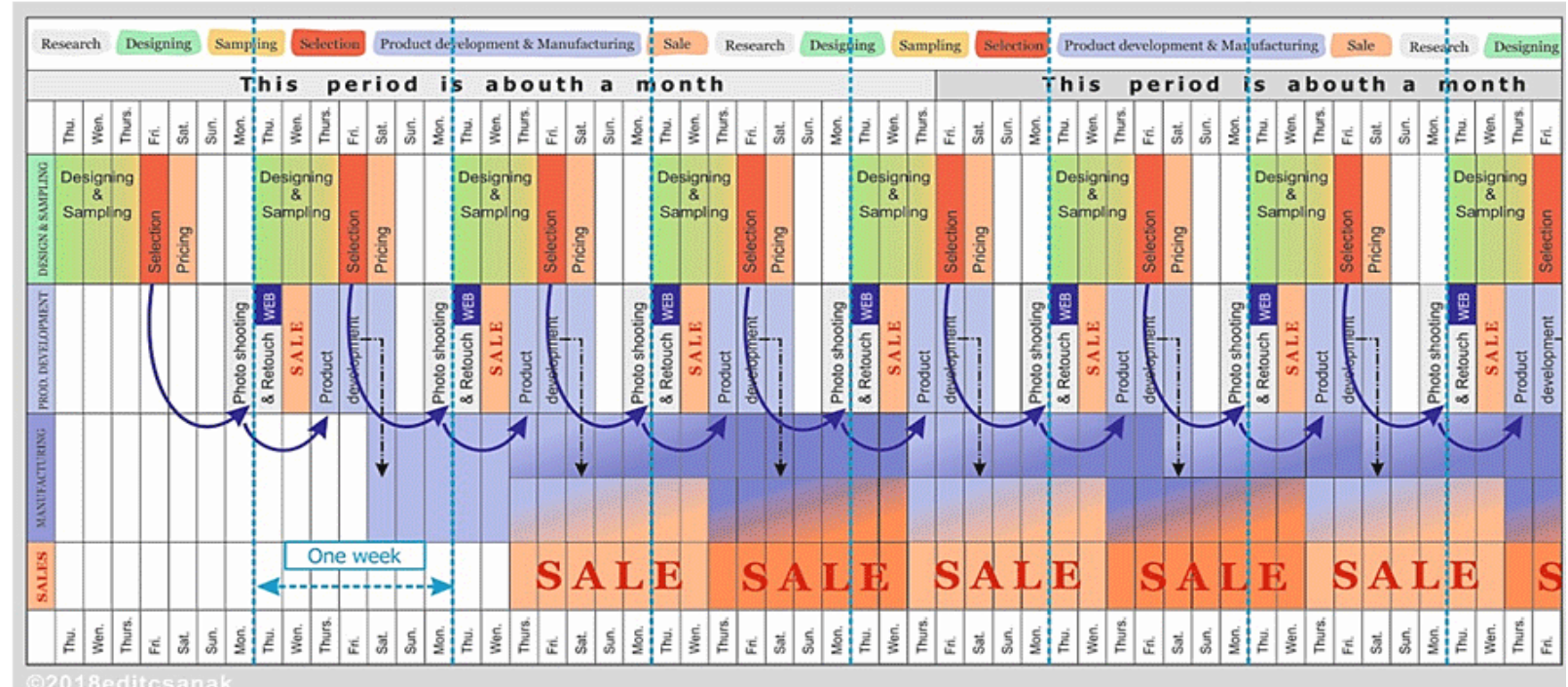

Figure 2: Schedule of the collection management of Fast Fashion supply chain

\section{The 'ctr+copy+paste' effect}

Due to the need for constant change, we faced further phenomena. Since brands are constantly updating their collections, designers are forced to create a large number of 'fresh designs' ready to be manufactured over-the-night.

Self-nominated trend forecasting agencies are armed with ready-made recipes to update the current style, helping the tired designers with the mashup of instant ideas. Mashup is a free transcription of the stylistic features of an existing thing - a remix. It is a digital genre that occurs in other non-digital genres in many forms, where its application generates novel phenomena. Keen mood board-maker style-collectors gather everything: images from publications, source material from the internet, color palettes, sketches, and inspirations, blending them with the clothes already made by others, available on the websites or public profiles of the brands. Thus, manufactured products are an inspiration for creating a "similar." Finally, it is not easy to distinguish whether the new item is a transcript of an existing one or just a style-theft.

Since the essence of fashion is in its massive proliferation, and the audience has always refused the radical change of the styles [5]. Most of the things we desire for we saw in our environment, thus: inspiration for collections is based on numerous private idea. Where and when did we see something in this transcultural world? Who would be able to say it!

Many manufacturers offer high-quality, controlled products that can be easily personalized (i.e., exchangeable from one label to another). This seemingly easy-to-use method ultimately resulted in some good-quality, but almost alike identity, thus unsellable brands collections. The fashion world faced the challenge of failing with an excellent product range that lacks brand credibility and uniqueness [13]. Lacking again the charming mistakes of the designer's artistic capricious - that will make the collection unique, we called for the beginning of a "craft movement" that was only a short walk away from the idea of sustainability.

Despite arguments that the fashion industry leaves great environmental footprint [20], quality assurance runs counter to the Fast Fashion concept. The clear purpose of Fast Fashion is not to make the style and quality of the garment durable, but to produce low-cost, non-quality and short-lived style articles [7]. The first movements occurred at the end of the 1980s, with more protests after 2014. Some writings analyze in detail the economic and social issues of Fast Fashion and the consequently growing sustainability trends [18] [4] [27].

\section{The trend of Sustainable Fashion}

Future of fashion is seen through the oculus of sustainability for over thirty years [6]. However, only when the most authoritative trend forecasters predicted that sustainability would (undoubtedly) evolve to be an integral part of the planning system where circular economy principles are embedded throughout the value chain [3], we started honestly to believe, that it will be a megatrend.

Sustainable thinking has become vital to fashion today. But looking better, fashion has only created a new, albeit remarkable, 
global trend, which in many cases is just a fake label - an excellent slogan, a phrase, a form of fashion business; is a quasi-devoted behavior that promises a quick reputation for struggling goals, but which lacks true content [27].

Making the fashion industry more sustainable is a genuinely praise worth direction, but how useful it is in fact? How timeconsuming is it? Some research claims that specific improvements are causing significant environmental pollution [11]. However; we really would like to do something! The movements launched to improve the economic, social, environmental, and better social judgment of the fashion industry achieved are significant results. Still: without changes in the methods of the global fashion industry, radical changes cannot be achieved.

\section{Issues of the supply chain management}

Stunned by the extent of our technological advancement, in which communication and information exchange are of primary importance, supply chain management has become a challenge for creative solutions [16]. Experienced designers who lead the wave of design methods are becoming a major part of the business and corporate plans. While having some professional and technical skills, it is essential to have a clear understanding of the different types of documents, although designers are often unlikely to understand their specific purpose and why it is important to apply them consistently and make them easy to interpret visually.

Smooth, seamless and meaningful communication, available, accessible and interpretable to all the actors during the Product Life Management (PLM) is essential for all the actors in the supply chain.

\section{The Gen Y designer}

According to some surveys [21], members of the Y generation, also known as millennials, are confident, independent, and goal-oriented, and are accustomed to working in the ROWE environment. The Gen Y fashion employees are already stirring things up in the workplace [13]. Habituated in a family and cultural background different to their parents, with a changed sense what they have permission to do [22], millennials are shaping their working environment and circumstances of work on their own needs. All this will have a significant impact on the business world and, like this, in the fashion industry.

$\mathrm{Y}$ Gen designer is interested in product ranges that can be arranged quickly, since the collection can be created faster than ever by using the CAD systems, and on-line assisting tools. Plenty of templates available as an appendix of the trend-books and a high number of online tools allow designers to develop collections simple and fast. Applications, such as Techpacker, No-Refresh or inkiROBO, are having, for instance, all features of the top custom-product design. With them, the designers can track different styles, vector designs and clip art graphics. They can work together with factories and convert everything to a technical package working online.

Designers are committed to new ways of operating, convinced that immediate sharing of the ideas by the available tools and collaborative work (web-based media) is more efficient than to spend unnecessary time with stand-alone, studio-based and in-depth study work. Popular work methods are at first glance fundamentally appropriate for employers, so designers are almost never asked if they can draw manually. A frequent reason why manually prepared sketches and artworks are skipped in the design process is the manual unskilled of the designer.

\section{Advantages of the web-based fashion PLM systems in the fashion industry}

Since the time available for designing and development of collections has been dramatically reduced (as presented on Fig 2), fashion companies over the world willingly use Product Lifecycle Management (PLM) systems, to reduce product development cost and to lead the time of manufacturing. Explicitly developed for the needs of the fashion industry, online PLM systems bring visibility, accountability and cooperation experience to fashion businesses. Proven and remarkable benefits make their use popular among the Y Gen designers.

The purpose of the time-consuming process of gathering trend information and inspiration altogether with the storywriting, making of hand-made mood boards, scrapbooking, the creation of hand-limned sketches and drawing is to maintain the evolution of the creative idea arisen from the 'concept-germs' seems to be skipped for reasons of time. However, these phase of the creative work is more fruitful than we might think at first.

\section{Technical, aesthetic and cognitive aspects of fashion design in the four steps of product development}

Making a product on a single drawing - especially in an industrial environment - has always been impossible. Designers use diverse types of drawings to design the visual and tactile appearance of the clothing at certain stages of the work, which also contribute to the development of creative idea [9].

\section{Four steps of the product development process}

By the general methodology (Fig 1), the process of product development is considered in 4 phases, as shown in Figure 3: 


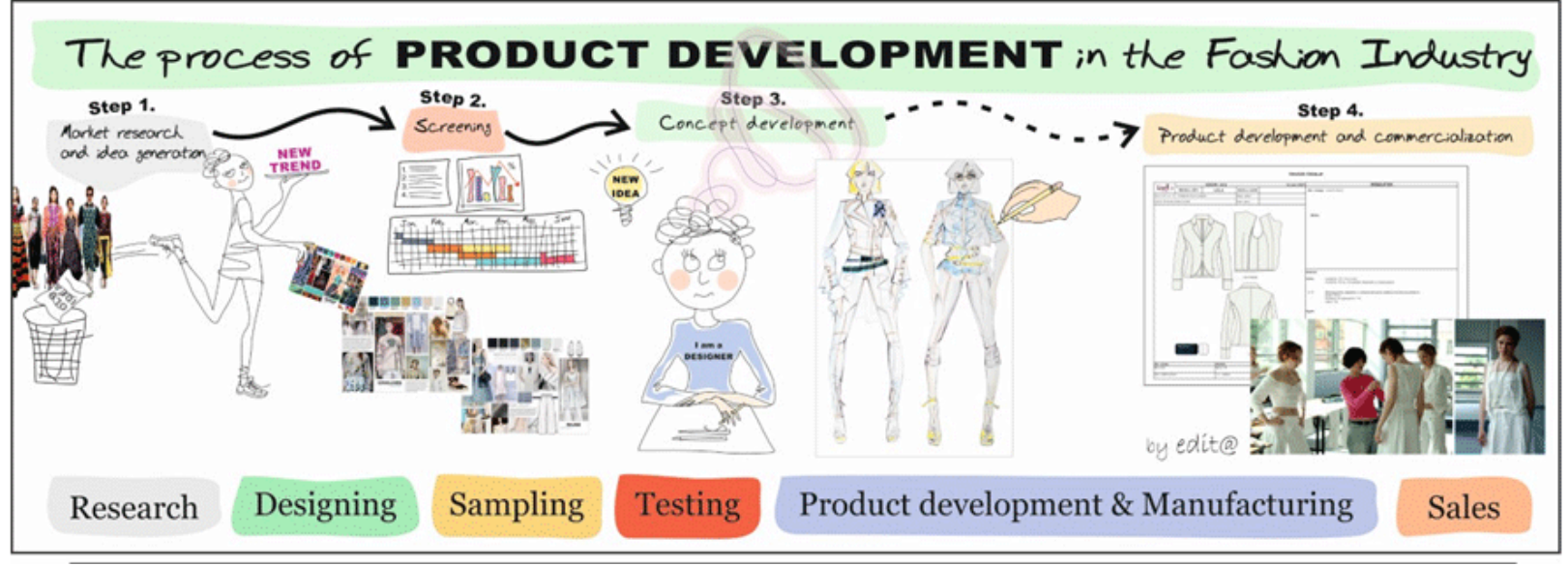

Figure 3: The steps of the product development in fashion industry according to the general theory

Phase 1. The process of market research and idea generation is research on inspiration, innovation opportunities, latest tendencies, and new concepts. It includes research on trend directions and study of information on color, shape, styling, market- and catwalk reports, and similar.

Phase 2. The screening process, and summary of the requirements: contains the brief of demands, and this is the step of creating the budget. Time scheduling (deadlines) are essential. Preparing of experimental samples, and mock-ups is also considered in this phase.

Phase 3. Concept development: Visualization of inspirations, and creation of the story. Mood boards and scrapbooks are vital: they help purification of the concepts which are difficult to get across verbally. The design process, as the stage of crafting and creation, and realization of 'immaterial ideas', is a vital, associative, imaginative, representative phase of the work. Considering of colors, shapes, proportion, silhouettes, patterns, and fabrics, furthermore, the selection of the surfaces, finishes, embroidery, decoration, styling directions and other details are made in this phase. This stage can hardly be finished only by computer; handsome products are born from freehand drawings!

Phase 4. Product development and commercialization are about the selection of the designs, preparing of garment worksheets and technical sheets (fashion flats, technical drawings), and graphics worksheets (for screen print, embroidery, etc.). Prototyping: flat pattern cutting, modeling, sampling, putting the look together. Styling, photography, promotion. Commercialization: market testing, and market introduction (pre-production process, production, the sale of the products).

\section{Aspects of the creative cognition}

"The designer feels visionary while designing." In this context, designing - in the meaning of 'drawing and sketching' - is of essential importance. This creative activity is also socio- technical nature: not just because fashion products are ultimately created for human needs, but for the reason that these activities involve immense interaction between the individuals and groups working on the products in complex social settings. Since the management of the supply chain, in which many people are involved in, is a complex socio-technical process, if the idea is explained only or mainly verbally, the visionary approach may raise lots of misunderstandings.

\section{The creative cognition and the problem-solving}

Fantasy and imagination are uncontrollable, in part subconscious activities of the brain, manifested in intensive communication of the frontal and back lobe. New ideas are born during the process of intensive activity of the brain called 'daydreaming,' with the key role of the associative parts of the brain, and are the result of the 'errors' of the perception (inability to focus) and cognition (a mixture of taught). Figure 4 illustrates this process.

While reading this text, the largest system of the brain, the visual system is very active. It is built from the following parts: eye, optic nerve, visual cortex and LGN with six areas within the thalamus. In co-operation with the left amygdale (responsible by the others for the short-term memory), a great part of your brain currently is working to interpret and memorize the reads. If feeling this content complex, a kind of pressure felt at the forehead (behind the eyes) reveals that we are trying to make a decision. If agreeing with the argumentation, a flush AHA experience took place. If missing the context while reading - because the thoughts are diverted, and thinking of something completely different from the above content - a daydreaming experience can be held responsible. Differently, FLOW is the experience of flying on the thoughts in motion, a feeling of emotional satisfaction. Figure 5 contributes to a better understanding of this process. 


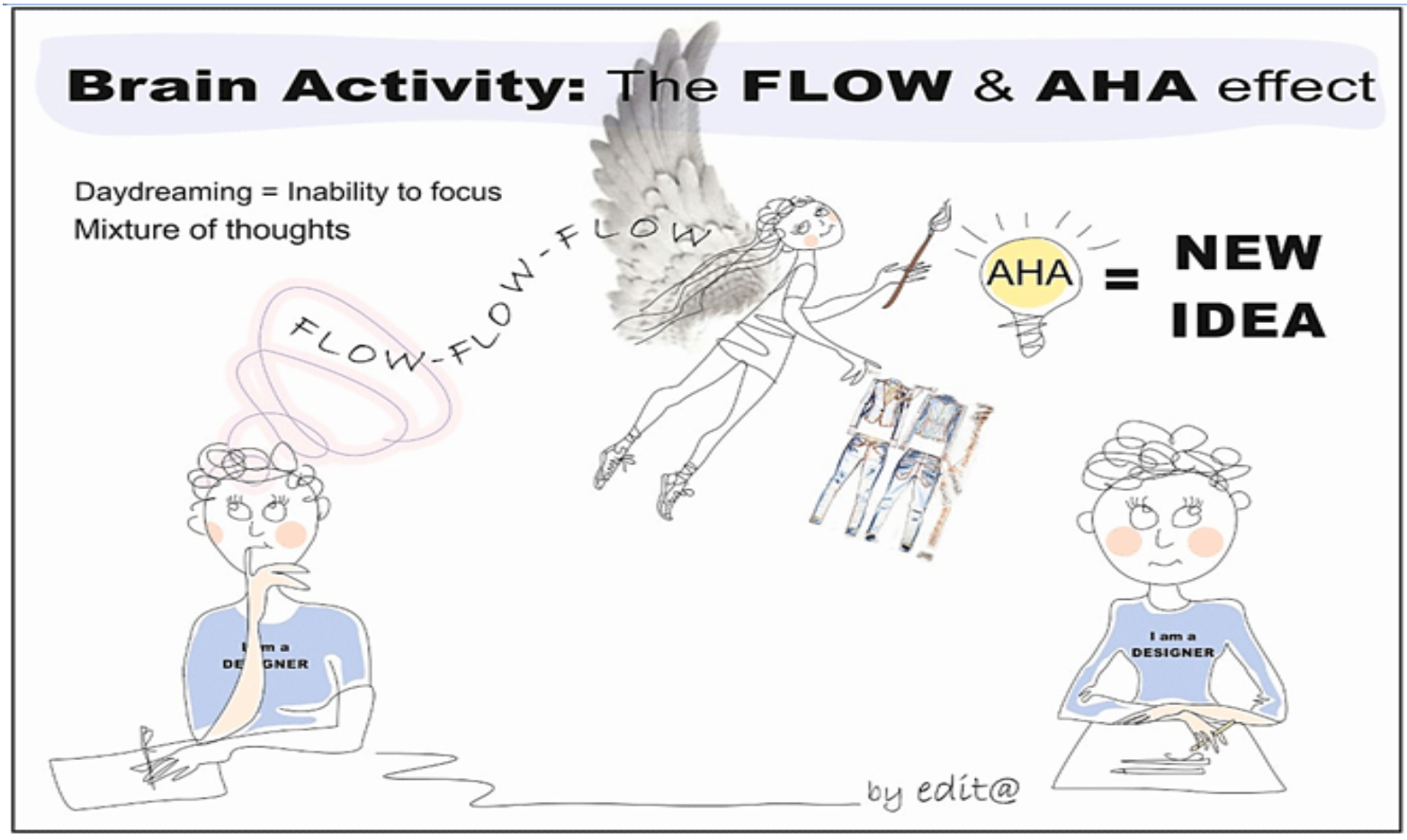

Figure 4: Brain activityes during the designer work: The FLOW and the AHA effect

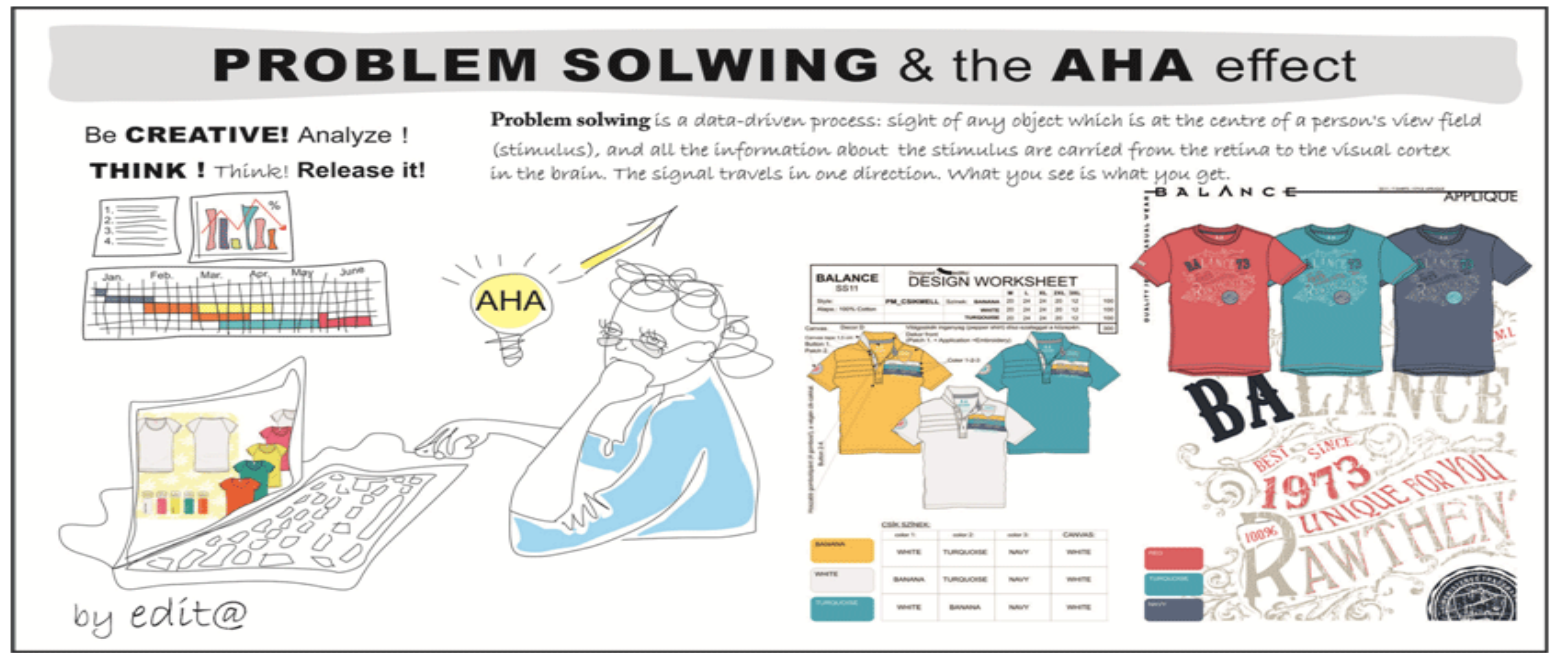

Figure 5: AHA-nature problem solving attitude during the design process

Differences in the size of parts of the brain and the pathways will determine how the brain will respond to any (visual) information. Such activities take place in different areas of the brain, and some of them, which are more emotional and associative nature, considered as a top-down approach of the creative cognition, according to the FLOW effect. Problem-solving thinking affects areas different than the previous; in this case, the bottom-up approach (problem-solving ability), basically related to the AHA effect is active. For example: if sitting in front computer and creating computer graphics, which need knowledge of the tools and features, logical thinking, ability of structural thinking, in terms of skilled usage of different tools, shaping of the objects, use of layers, colour palettes, patterns, font, etc., then the problem solving ability is more active in suppressing the fantasy. 


\section{The Genre Of Fashion Design}

Fashion design, in its meaning of a plan or drawing produced to show the look and function of a garment before it is made, is an essential tool of the designer. It is a distinctive artistic genre, evolving parallel to fashion designing. Usually, it is not a condition to be a good fashion illustrator to be a skilled designer. Many famous designers are the well-known lousy drawers; good drawing skills undoubtedly help the work and bring the designer closer to success [15]. A big amount of literature is theorizing on the cognitive process of creative work, just marginally dealing with the topic of fashion design. Although theories on artistic performance and creativity can never be enough 'empirical,' and the process can never be understood well enough, fashion designing can also be examined through the cognitive, apperceptive and representative process [10].

Which kind of drawing to be preferred to have an innovative collection? Entire types of fashion drawing and design are necessary because of their representative functions, and as stages of the evolution of the creative idea, they are also crucial for the designer too [8]. However, this last aspect raised few new issues, which became typical for the ROWE work scheme.

\section{Types of fashion design, and their purposes in designing and product development process}

Different types of fashion design exist in practice. They are usually called fashion design, but they are of different types, designed for different purposes and with many available techniques. The basic three types, the fashion sketch, the artwork, and the fashion flat are considered as phases of the progress of the creative idea.

Fashion sketch is a quick freehand sketch that tracks the evolution of the concept, usually found in the context of many others made to express the first idea. Sketches can be made by applying different tools (marker, pen, aquarelle, pencil) and can be hardly made by CAD. Such fashion illustration is made at a glance; however they are suggestive, they are still informal and non-concrete, containing just some of the information essential for the production. Thus, only some of them are to give precise information to the technicians.

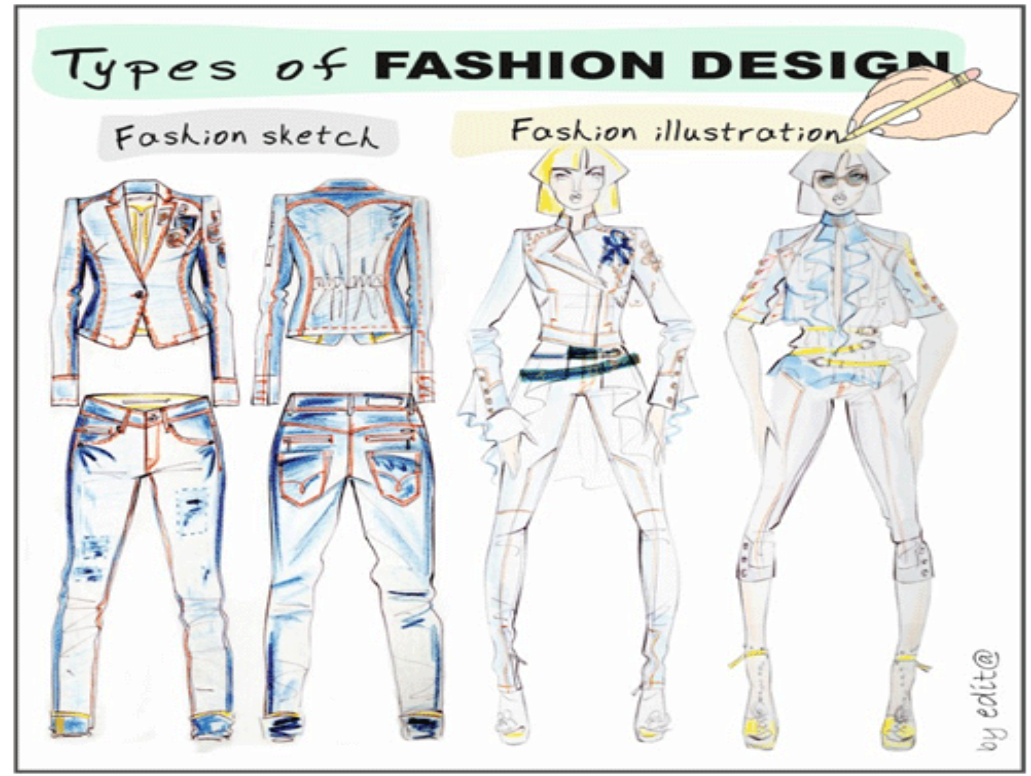

Figure 6: Fashion Sketch And Fashion Illustration

Fashion artwork, similarly to the fashion illustration, is a slightly detailed drawing of the garment presented on a figure. Such designs are often used to show the essence of the spirit of collections. Artworks are usually made in full color and are used to communicate a design idea to third parties. Its classic type is the manual drawing. Since made manually, their creation is a time-consuming process. Excellent drawing skills are essential; a precise knowledge of the human anatomy and proportions, together with the experience in drawing of textiles, drapery, patterns. A particular understanding of different paper qualities, drawing and painting tools (pencils, markers, brushes, crayons and similar) is also crucial to make them. The granularity of these drawing will be, depends on the intention of the designer: some of them are slightly detailed and non-concreate. Depending on the specific style of the designer the drawings can be more or less easily interpreted: the drawings may be illusionistic, the mannequins have stylized proportions, or sometimes, the representation is entirely abstract. Given, that they are handmade, their value is high, and their aesthetic and artistic assessment is an essential part of valuing of the artistic performance.

Artworks created with CAD can be prepared by a wide range of software provides an approach to the drawing process without all the fuss over it! To create them is enjoyable, but timeconsuming work - even for a trained designer. 


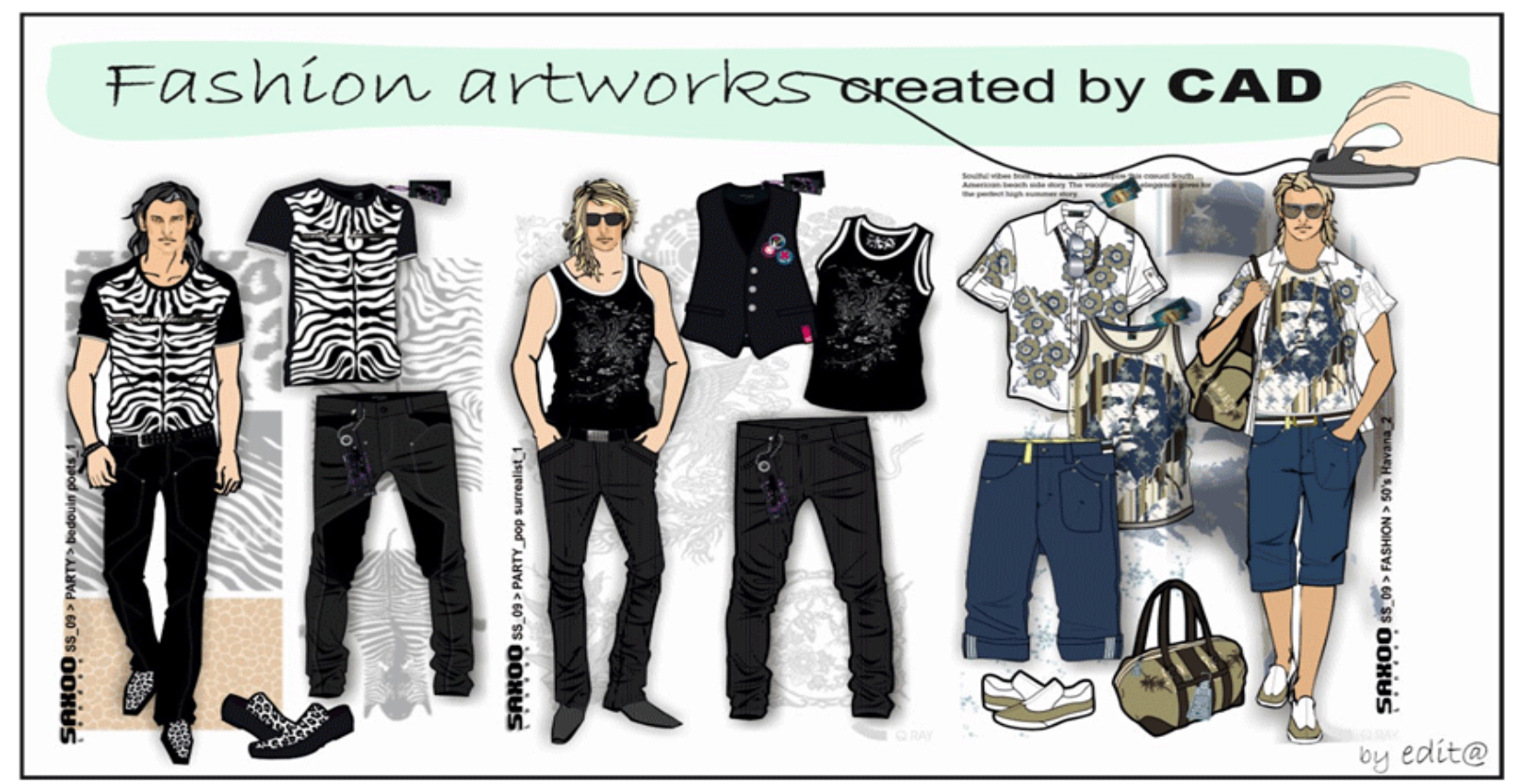

Figure 7: Fashion artworks created by CAD system with Corel Draw X3 software

Fashion flats are the form of illustration of the garment without a figure. These are used generally in garment worksheets, and technical sheets, and are typically submitted to the manufacturer to prepare the samples. Such drawing can be made by hand too. However, today these kind of technical drawings are preferably arranged by CAD systems with design software, since of their advantages; a lot of templates, patterns, color palettes can be easily applied, and the work with the added graphics designs is much more comfortable (Figure 8).

Nowadays a series of designer-friendly software for preparation of technical drawing and fashion flat have been developed for the less skilled, that operate with a wide range of templates, patterns, and sheets customized for different needs (Fig 9). On-line PLM applications particularly operate similar to this designer software. Available tools allow comfortable and fast preparation of fashion flat applied at garment worksheets and tech-sheets, appropriate to give accurate, exactly precise information about the garment for the technical staff and manufacturers. Such software allows advanced users dramatically to reduce both production and design time that is an essential factor in ROWE environment of the fashion PLMs.

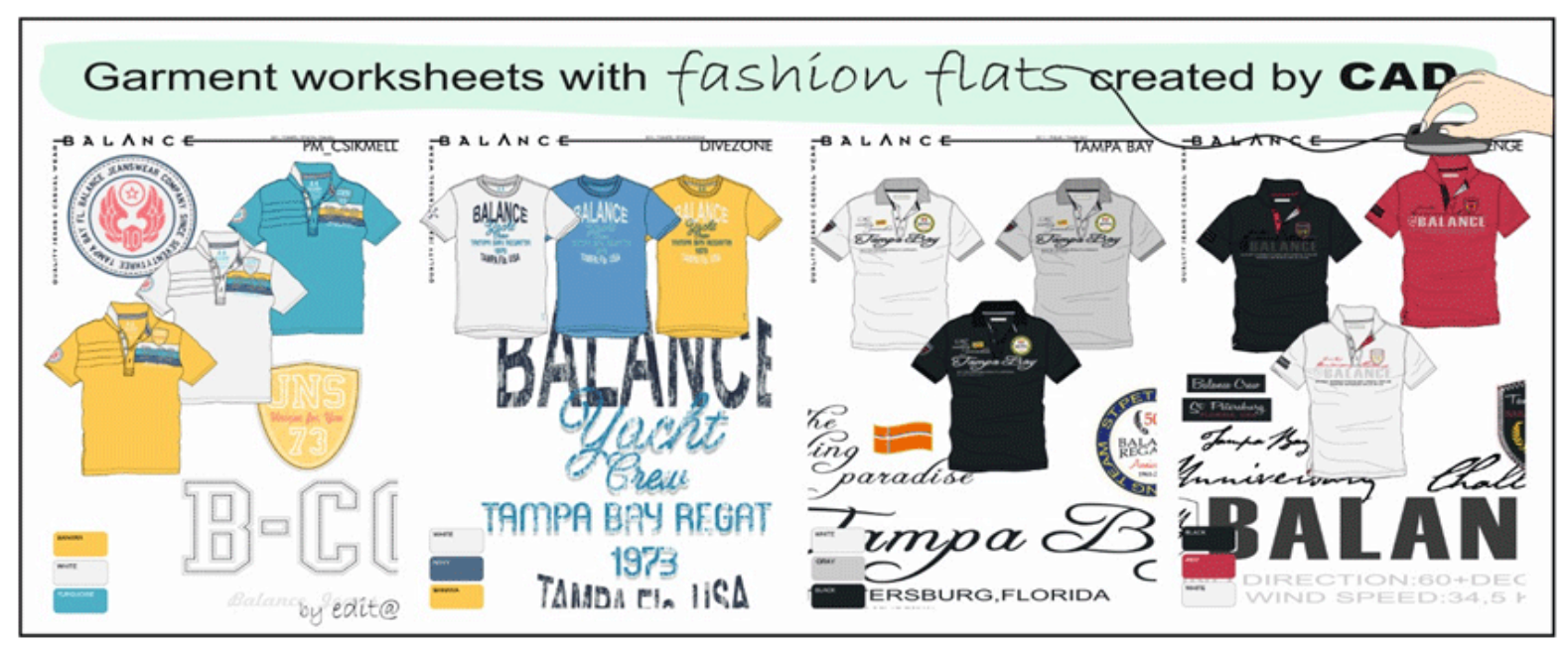

Figure 8: Fashion Flats On The Garment Worksheets Created By CAD System With Corel Draw X3 Software 


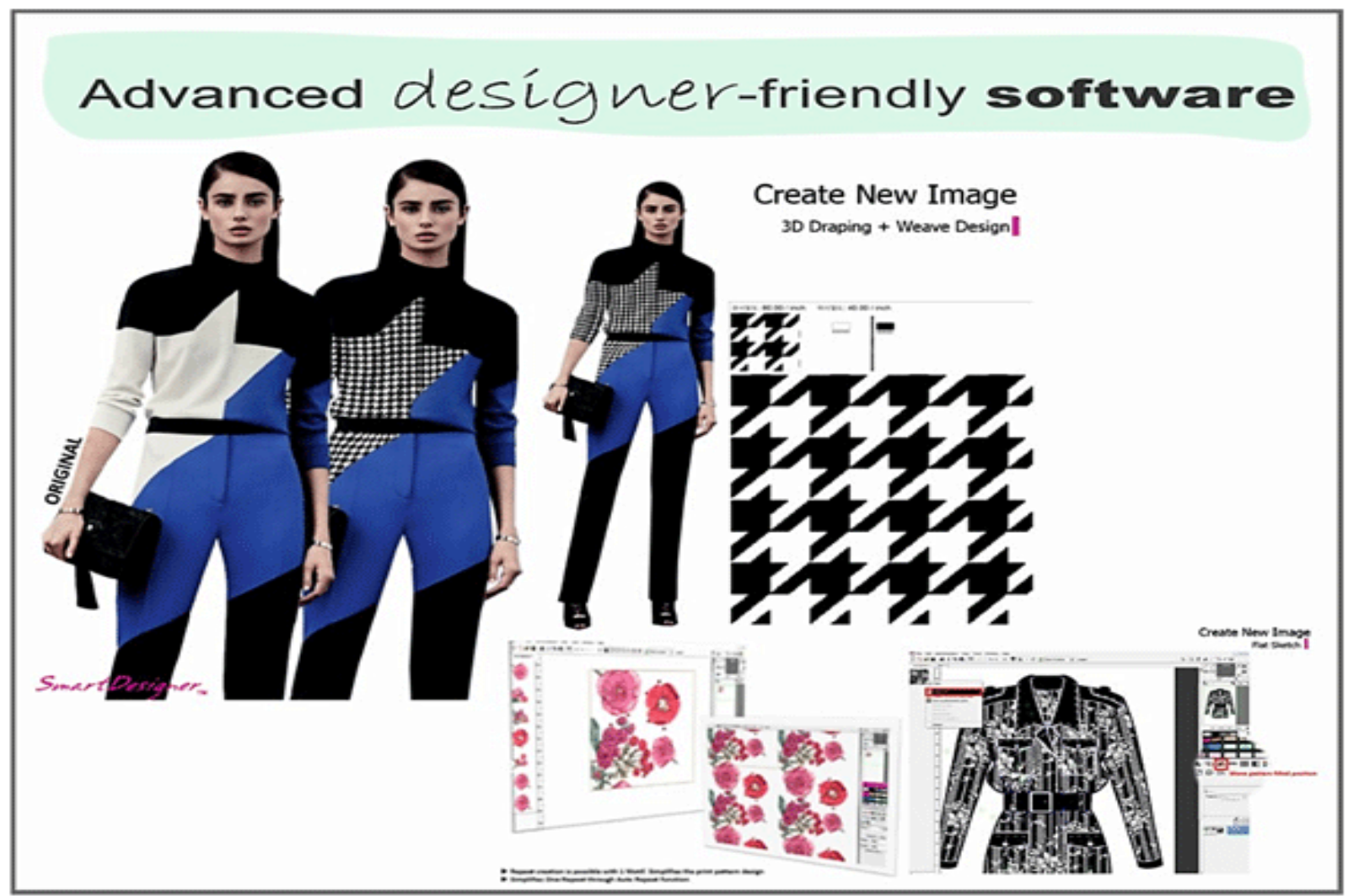

Figure 9: Advanced technology designed for ROWE-enviroinment fashion PLMs

3D designs can be shared virtually across multiple platforms. Systems such as Morgan Tecnica, Lectra, or Gerber (Accu Mark 3D) offer the largest range of high performing software packages, perfectly integrated and highly customizable for production optimization. For instance Gerber's virtual fashion technology software CLO, which is revolutionizing the design process, helping the fashion to be more sustainable. However, as analyzed, the creation of such virtual images are led by the AHA-effect and made in a bottom-up approach [10]. Their look is usually perfect, giving the experience of reality. Although one main concern of the designers (graphic artists, painters) has always been to achieve a maximum of photorealistic realistic imagery, the expressive representation - resulting from the artist's individuality and specific style (according to 'errors' occurring from the top-down processing) has always been more effective than any realistic imaging.

Such it is right for fashion design: working in a ROWE environment of Fast Fashion PLM supports speed, efficiency, and realistic representation. Problem-solving, analytical thinking, the use of CAD systems, handling of different facilities, software, tools and similar need logical and rational, thinking, actions for which the hemisphere of the left brain is known to be responsible. We are talking, writing, reading and counting with the left hemisphere. By contrast, the creative imaginary, 'curing' with the wings of the FLOW-effect, comes from the right hemisphere responsible for imaginative holistic thinking; we experience the emotions, we draw, listen and enjoy music, see the relationships and use our intuition with our right brain, which is creative and artistic. Parts of the brain left, and right hemisphere, frontal and back lobe is in interaction during the creative process. It is for sure to know which effects, which of the two hemispheres, what kind of approach has been applied to create it.

\section{Conclusion}

This article attempted to highlight the use of the classic didactic method compared to the shortcomings of routine in the ROWE Fast Fashion environment in the context of the changed mental activities that occur during the design process. It analyzed the stages of fashion designing and collection development, which phases require a various type of fashion drawing, for a different purpose. The less or more detailed sketches, artworks, vector designs, fashion flats used on technical sheets, have their function in the designing process, and help the designer filtering and developing the ideas. However, some autonomous one-piece masterworks are often made 'on a glance,' based on a single pen-sketch, without having any technical illustration or technical paper, but if a complex technical crew is involved in the manufacturing process, a sketch, or a non-concrete, abstract artwork does not contain the information necessary for manufacturing. Consequently: much unnecessary work, wasted 
time, excess and unsold samples were taken, which could have been avoided if having a proper 'document.'

Fashion illustration, drawings, and fashion flats, similarly to all the designs used for the preparation of garment worksheets, technical sheets, and tech packs, play an important role in the collection development. Designers can hardly make a difference between them and understand their importance in work; however, their proper use has a huge impact on sustainable collection development: this paper aimed to draw attention to particular matters of the design process, and the impact of the creative work on related topics on sustainable growth of the brands.

Creative opportunities of the modern technology influence our present and determine the future. Similarly, the prospect of fashion will be influenced by creative possibilities and novel IT solutions. However, applications used in the future cannot replace the 'classical manner' of designing. Todays Fast Fashion industry puts great pressure on fashion professionals to constantly review the effectiveness of their work. The usage of advanced tools, however, does not guarantee the productivity of the professional work and reducing the environmental impact of the fashion industry in straight proportions. Sustainably designing a fashion collection means more than creating a product range, according to demands of the changed work environment of the Fast Fashionrun PLM. Application of new working methods creates deficiencies that may have a huge future impact. Even expectations to the designer changed - quantitative and qualitative expectations are high -, widespread of the Sustainable Fashion can be considered as 'just-another-trend' if lacking loads such as design awareness, and creative imagination of the designer.

\section{References}

1. Anders S, Mcafee A, Dessain V. Zara: IT for Fast Fashion. Harvard Business Review. 2004.

2. Blanchet V. Performing market categories through visual inscriptions: The case of ethical fashion. Organization, forthcoming. 2018;25(3):374-400.

3. Business of Fashion. The State of Fashion 2018. The Business of Fashion and McKinsey \& Company. 2017.

4. Ceren A, Duygu T. Sustainable supply chain management in the fast fashion industry: An analysis of corporate reports. European Management Journal. 2014;32(5):837-849.

5. Csanák E. Creativity and technology - Generation and attitude change in the apparel industry. TNP2013-VII Textile Science \& Economy Conference. Zrenjanin. 2013.

6. Csanák E. Eco-Friendly Concepts and Ethical Movements in the Fashion Industry. Conference ITC\&DC. Dubrovnik. 2014.

7. Csanák E. Development of garment supply chain model for pronto moda company. TNP2015-VII Textile Science \& Economy Conference. Zrenjanin: University of Novi Sad, Technical Faculty Mihajlo Pupin 2015
8. Csanák E. Kollekcióalakítás. Budapest: NSZFI. 2015.

9. CsanákE. The Art of Garment Worksheet: Creative, Visual and Technical Features of Creative Documents. International Joint Conference on Environmental and Light Industry Technologies. Budapest. 2017.

10. Csanák E. The CAL: cognitive, apperceptive and representative aspects of fashion design - Side note to neuroaesthetic theory. IOP Conf. Series: Materials Science and Engineering 254 (2017) 172008. 17th World Textile Conference AUTEX 2017- Textiles - Shaping the Future: IOP Publishing. 2017.

11. De Falco F, Gullo MP, Gentile G, Di Pace E, Cocca M, Gelabert L, et al. Evaluation of microplastic release caused by textile washing processes of synthetic fabrics. Environ Pollut. 2018;236:916-925. doi: 10.1016/j. envpol.2017.10.057

12. Edit C. Engineering Design Communication for the Fashion Industry. TNP2016. Zrenjanin. 2016.

13. Friese L, Jowett $\mathrm{C}$. The six ways Generation $\mathrm{Y}$ will transform the workplace. 2013.

14. Georg S. Fahion. American Journal of Sociology. 1957;62(6.):541-558.

15. Gwilt A. A Practical Guide to Sustainable Fashion (Basics Fashion Design). First Edition. 2014; Fairchild Books; New York

16. Harrison A, Van Hoek R. Logistics Management and Strategy: Competing Through the Supply Chain. Third Edition. 2008; Pearson Education Limited;Harlow.

17. VS Ramachandran, William Hirstein. The Science of Art - A Neurological Theory of Aesthetic Experience. Journal of Consciousness Studies. 1999;6(6-7):15-51.

18. Annamma Joy, John F Sherry, Jr Alladi Venkatesh, Jeff Wang, Ricky Chan. Fast Fashion, Sustainability, and the Ethical Appeal of Luxury Brands. Fashion Theory.2012;16(3):273-296.

19. Kühnl S. Editors Letter. Sportswear International. 2013;245:8.

20. Luz C. Waste Couture: Environmental Impact of the Clothing Industry. Environ Health Perspect. 2007;115(9): A449-A454.

21. Meier J, F Austin S, Crocker, M Stephen. F Generation Y in the Workforce: Managerial Challenges. The Journal of Human Resource and Adult Learning. 2010;6(1):68-78.

22. Morton LP. Targeting generation Y. Public Relations Quarterly. 2002;47(2):46-48.

23. Martin Christopher, Robert Lowson. Creating agile supply chains in the fashion industry. International Journal of Retail and Distribution Management. 2004;32(8):367-376

24. Semir Z. Art and the Brain. Daedalus. 127(2):71-103.

25. Sullivan P, McCarthy J. An experiential account of the psychology of art. Psychology of Aesthetics, Creativity, and the Arts. 2009;3(3):181-187. 26. Watson S. The Way We Dress Now. The Sunday Times. 2006.

27.Csanák E. Sustainable Fashion: Limiting a Singularity - Advanced Glossary to an Article. Int J Fashion Technol Textile Eng. 2018;1(1):1-5. 